\title{
Do dietary patterns in older men influence change in homocysteine through folate fortification? The Normative Aging Study
}

\author{
Kim TB Knoops', Avron Spiro 3rd ${ }^{2}$, Lisette CPGM de Groot ${ }^{1}$, Daan Kromhout ${ }^{1}$, \\ Wija A van Staveren ${ }^{1}$ and Katherine L Tucker ${ }^{3, *}$ \\ 'Division of Human Nutrition, Wageningen University, Wageningen, The Netherlands: ${ }^{2}$ Boston University \\ School of Public Health and the Veterans Affairs Boston Healthcare System, Boston, MA, USA: ${ }^{3}$ Jean Mayer US \\ Department of Agriculture Human Nutrition Research Center on Aging, Tufts University, Boston, MA 021 11, USA
}

Submitted 17 August 2007: Accepted 3 November 2008: First published online 24 December 2008

\begin{abstract}
Objective: We aimed to describe the difference in B-vitamin intake and in plasma B-vitamin and homocysteine concentrations before and after folic acid fortification, in relation to dietary patterns.

Design: The Normative Aging Study (NAS) is a longitudinal study on ageing. Between 1961 and 1970, 2280 male volunteers aged 21-80 years (mean 42 years) were recruited. Dietary intake data have been collected since 1987 and assessment of plasma B vitamins and homocysteine was added in 1993.

Setting: Boston, Massachusetts, USA.

Subjects: In the present study, 354 men who had completed at least one FFQ and one measurement of homocysteine, both before and after the fortification period, were included.

Results: Three dietary patterns were identified by cluster analysis: (i) a prudent pattern, with relatively high intakes of fruit, vegetables, low-fat milk and breakfast cereals; (ii) an unhealthy pattern, with high intakes of baked products, sweets and added fats; and (iii) a low fruit and vegetable but relatively high alcohol intake pattern. Dietary intake and plasma concentrations of folate increased significantly $(P<0 \cdot 05)$ among all dietary patterns after the fortification period. Homocysteine tended to decrease in supplement non-users and in subjects in the high alcohol, low fruit and vegetable dietary pattern (both $P=0 \cdot 08$ ).

Conclusions: After fortification with folic acid, folate intake and plasma folate concentration increased significantly in all dietary patterns. There was a trend towards greatest homocysteine lowering in the high alcohol, low fruit and vegetable group.
\end{abstract}

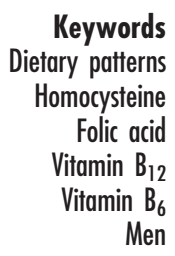

Elevated plasma homocysteine has been associated with increased risk of CVD, cognitive decline, hip fractures and mortality $^{(1-7)}$. Supplements containing folic acid have been shown to effectively reduce homocysteine in subjects with normal and elevated baseline concentrations ${ }^{(8)}$. Consumption of fruit and vegetables has been negatively associated, while coffee drinking and alcohol consumption have been positively associated with homocysteine concentration $^{(9,10)}$. Because of high collinearity among nutrients and food groups, there is increasing interest in the investigation of dietary patterns rather than single foods or nutrients in relation to homocysteine ${ }^{(11)}$. In one study of Chinese adults, a dietary pattern high in refined cereal grains was associated with a high prevalence of elevated plasma homocysteine and low B-vitamin concentrations, whereas those following a pattern high in fruit and milk had the lowest plasma homocysteine and highest B-vitamin concentrations ${ }^{(11)}$. In a study of Irish men, a prudent dietary pattern, derived by cluster analysis, was associated with a lower homocysteine concentration $^{(12)}$. Fung et al. found that a prudent dietary pattern, derived by factor analysis, was positively correlated with plasma folate and inversely with homocysteine concentration in a large US cohort ${ }^{(13)}$.

In 1996, the US Food and Drug Administration issued a regulation requiring that all enriched grain products be fortified with $140 \mu \mathrm{g}$ folic acid/100 g cereal-grain product to reduce the risk of neural-tube defects ${ }^{(14-17)}$. The prevalence of deficient plasma folate, and to a lesser extent of elevated total plasma homocysteine, has been reduced after this fortification $^{(15,16)}$. However, to our knowledge, the effect of folate fortification has not yet been investigated in relation to dietary patterns. Individuals with certain dietary patterns may differ from others in response to the fortification. For 
example, individuals with an unhealthy dietary pattern may have greater benefit from folate fortification than individuals with a healthy dietary pattern, as they are more likely to consume the refined grains that were fortified. Therefore, we investigated the difference in B-vitamin intake and in plasma B-vitamin and homocysteine concentrations before and after folic acid fortification, within dietary patterns derived by cluster analysis, in elderly men participating in the Normative Aging Study (NAS).

\section{Methods}

\section{Subjects}

The NAS is a longitudinal study which started in 1963 by recruiting men, 21 to 80 years of age, and free if heart disease and other major health problems, around Boston, Massachusetts, USA. Details of the study are described elsewhere $^{(5,18)}$. Briefly, participants were invited every 3-5 years to complete a health examination and several questionnaires. Dietary intake data have been collected since 1987 and assessment of plasma B vitamins and homocysteine was added in 1993. For the present study, we included men who had completed at least one FFQ and who had at least one measurement of homocysteine concentration, both before (prior to 1 October 1996) and after (since 31 August 1997) the fortification period. This resulted in 354 men.

\section{Dietary intake}

Dietary intake was assessed with a semi-quantitative FFQ, which requests that participants record the number of times they consume each of 126 food items ${ }^{(5)}$. This questionnaire has been validated for intake of these $\mathrm{B}$ vitamins against plasma measures ${ }^{(19,20)}$. The 126 food items were converted into twenty-one food groups: regular milk and dairy products; low-fat milk and dairy products; fruit; vegetables; sweets; meat; poultry; added fats; legumes; eggs; fish; grains; bread and baked goods; breakfast cereals; potatoes; snacks; tea and coffee; alcohol; other drinks; nuts; and soups.

For subjects with more than one FFQ before or after fortification, the average frequencies of consumption for each food group were calculated and these averages were used in the cluster analyses to best estimate usual intakes. The average number of FFQ for each subject was $2 \cdot 5$ (SD $0.8)$ before and $1.6(\mathrm{SD} 0.5)$ after fortification. The FFQ also contains questions on use of multivitamin or single vitamin or mineral supplements. Any individuals responding affirmatively to use of a supplement containing folic acid, vitamin $B_{12}$ or vitamin $B_{6}$ were classified as supplement users.

\section{Blood collection and analysis}

Blood was drawn at the Veterans' Administration clinic after an overnight fast. Plasma was immediately separated and stored at $-80^{\circ} \mathrm{C}$. Samples were transferred on dry ice to the Jean Mayer US Department of Agriculture Human Nutrition Research Center on Aging, where they were again stored at $-80^{\circ} \mathrm{C}$. Total homocysteine in plasma was measured using an adaptation of the method described by Araki and Sako ${ }^{(21)}$. The $\mathrm{CV}$ for this method in our laboratory, which is highly experienced in homocysteine measurement, is $4 \cdot 0 \%{ }^{(22)}$. Plasma folate and vitamin $\mathrm{B}_{12}$ concentrations were measured by radioassay with a commercially available kit from Bio-Rad (Hercules, CA, USA). The CV for these assays are $4 \cdot 7 \%$ for vitamin $\mathrm{B}_{12}$ and $4.3 \%$ for folate. Plasma vitamin $\mathrm{B}_{6}$ (pyridoxal-5phosphate, PLP) was measured enzymatically by tyrosine decarboxylase ${ }^{(23)}$. The CV for this assay is $5 \cdot 0 \%$ in our laboratory. For most of the subjects, only one homocysteine measurement was available before fortification (mean number of measurements $1 \cdot 08$ (SD 0·23)). Therefore, we used the first measurement of blood before (time 1) and after (time 2) fortification for each of the men. The mean time between these two blood collections was $3 \cdot 1(\mathrm{SD} 0 \cdot 5)$ years.

\section{Assessment of other variables}

Date of birth and information about smoking and education (years) were collected by questionnaire at time 1 . Measurements of BMI $\left(\mathrm{kg} / \mathrm{m}^{2}\right)$, waist:hip ratio and serum creatinine $(\mathrm{mg} / \mathrm{dl})$ were available for all subjects at time 1 .

\section{Statistical analysis}

Statistical analyses were performed using the SAS statistical software package version 9.1 (SAS Institute, Cary, NC, USA). Cluster analysis was used to derive dietary patterns. To obtain more stable dietary patterns, cluster analyses were performed on all available dietary data in the larger study (i.e. not only the 354 men with complete data pre- and post-folate fortification), using the average of all available FFQ during the same time period ( $n$ 2263). We removed FFQ resulting in reports of intake of any food item at $\geq 5 \mathrm{sD}$ from the mean for the item ( $n 171,8 \%$ of total FFQ) to avoid any undue influence of outliers on cluster formation. Cluster analysis was performed using FASTCLUS in SAS version 9.1. We ran the clustering procedure with a varying number of clusters (three to six). The final solution was selected based on the most meaningful appearance of patterns, balancing sample size and clarity of separation.

Mean age, BMI, waist:hip ratio, waist circumference, creatinine, alcohol intake and energy intake were calculated and compared across the clusters at baseline with the general linear models (GLM) procedure in SAS, using Tukey's adjustment for multiple comparisons. Smoking status was compared across the three clusters with the $\chi^{2}$ statistic. Because visual plots of the data showed distributions that were close to normal, the untransformed variables were used in the analyses to maximize interpretability. Differences between pre- and post-fortification measures of intake and values of plasma $B$ vitamins 
and homocysteine were calculated in the full group of men ( $n$ 354), within and between supplement users ( $n$ 101) and supplement non-users ( $n$ 253, as defined at baseline) and within and between dietary patterns, and tested with the GLM procedure using Tukey's adjustment for multiple comparisons. All models were adjusted for age (years), education (years), smoking status (current or former, each $v$. never), plasma creatinine ( $\mathrm{mg} / \mathrm{dl})$, energy intake (MJ), waist:hip ratio and B-vitamin supplement use. All analyses were repeated for supplement nonusers. BMI was tested as an additional confounder, but did not affect the results.

\section{Results}

The cluster analysis resulted in three distinct dietary patterns: (i) the first was characterized by high intakes of fruit, vegetables, low-fat milk, breakfast cereals and fish (a prudent dietary pattern); (ii) the second by high intakes of bread and baked products, coffee, added fats, sweets, regular milk and dairy, meat, soft drinks and potatoes (an unhealthy dietary pattern); and (iii) the third by low intakes of fruit and vegetables and higher intake of alcohol (Table 1). Men in the prudent pattern were significantly older and less likely to smoke compared with the other patterns (Table 2).

Men in the low fruit and vegetable, high alcohol pattern reported significantly lower energy intake relative to men in the other two patterns. Over the observed time period, homocysteine concentrations decreased, although this did not reach significance for the full group $(P=0 \cdot 10)$. The decrease in homocysteine approached significance $(P=0 \cdot 08)$ in supplement non-users, but not in supplement users. Plasma folate $(P<0 \cdot 0001)$, vitamin $\mathrm{B}_{12}(P<0.05)$ and vitamin $\mathrm{B}_{6}(P<0.0001)$ increased in the full group of men (Table 3 ) and in supplement nonusers $(P<0.0001,<0.05$ and $<0.0001$, respectively). Among supplement users, only plasma folate increased significantly $(P<0 \cdot 0001)$. At the same time, dietary intake from foods (including fortified foods) increased significantly only for folate $(P<0 \cdot 0001)$. Dietary intake of vitamin $\mathrm{B}_{12}$ decreased significantly in the full group $(P<0 \cdot 001)$ and in supplement non-users $(P<0 \cdot 01)$, while intake of vitamin $\mathrm{B}_{6}$ tended to decrease in supplement users $(P=0 \cdot 08)$. Baseline plasma folate, vitamin $\mathrm{B}_{12}$ and vitamin $\mathrm{B}_{6}$ were each significantly higher and homocysteine concentrations lower in supplement users $v$. supplement non-users $(P<0 \cdot 05$ to $<0 \cdot 0001)$.

Before fortification, homocysteine concentrations appeared to be lower, and plasma B-vitamin concentrations higher, in the prudent pattern compared with the unhealthy and low fruit and vegetable, high alcohol patterns, although these differences were not significant (Table 4). Dietary intakes of folate and vitamin $\mathrm{B}_{6}$ were higher in the healthy pattern compared with the other two $(P<0 \cdot 05$ to $<0 \cdot 001)$. After fortification, plasma folate increased significantly in all three dietary pattern groups $(P<0 \cdot 001$ for prudent, $P<0.0001$ for other two). Plasma vitamin $\mathrm{B}_{6}$ increased significantly in the prudent $(P<0 \cdot 05)$ and low fruit and vegetable, high alcohol patterns $(P<0 \cdot 001)$. There were no significant differences in homocysteine, although the

Table 1 Mean daily number of servings of food groups by dietary pattern: subset of men $(n 354)$ in the Normative Aging Study, Boston, Massachusetts, USA

\begin{tabular}{|c|c|c|c|c|c|c|}
\hline Food group & \multicolumn{2}{|c|}{$\begin{array}{l}\text { Prudent } \\
\text { (n 49) }\end{array}$} & \multicolumn{2}{|c|}{$\begin{array}{l}\text { Unhealthy } \\
\text { (n 105) }\end{array}$} & \multicolumn{2}{|c|}{$\begin{array}{l}\text { High alcohol, low fruit \& } \\
\text { vegetables } \\
(n 200)\end{array}$} \\
\hline Full-fat milk and dairy & $1 \cdot 0$ & $1 \cdot 3$ & $1 \cdot 4 \ddagger$ & $1 \cdot 3$ & $1 \cdot 1$ & $1 \cdot 1$ \\
\hline Low-fat milk and dairy & $1 \cdot 1 \ddagger$ & $1 \cdot 1$ & $0 \cdot 7$ & 0.9 & $0 \cdot 6$ & 0.8 \\
\hline Sweets & $1 \cdot 0$ & $1 \cdot 0$ & $2 \cdot 8 \ddagger$ & $2 \cdot 5$ & $0 \cdot 8$ & $1 \cdot 0$ \\
\hline Meat & 0.7 & 0.7 & $1 \cdot 1 \ddagger$ & 0.7 & 0.8 & 0.5 \\
\hline Poultry & $0 \cdot 4$ & $0 \cdot 3$ & 0.3 & $0 \cdot 3$ & $0 \cdot 3$ & 0.2 \\
\hline Fats & $1 \cdot 7$ & 0.9 & $2 \cdot 8 \ddagger$ & $1 \cdot 6$ & $1 \cdot 6$ & $1 \cdot 0$ \\
\hline Legumes & $0 \cdot 4 \ddagger$ & $0 \cdot 3$ & $0 \cdot 2$ & $0 \cdot 2$ & $0 \cdot 2$ & 0.2 \\
\hline Breakfast cereals & $0.9 \ddagger$ & 0.6 & 0.6 & 0.5 & 0.5 & 0.5 \\
\hline Potatoes & 0.5 & $0 \cdot 3$ & 0.6 & $0 \cdot 3$ & $0 \cdot 4$ & $0 \cdot 2$ \\
\hline Snacks & 0.6 & 0.5 & 0.6 & 0.6 & 0.5 & 0.4 \\
\hline Drinks & $0 \cdot 8$ & 0.9 & $0.9 \ddagger$ & $1 \cdot 3$ & $0 \cdot 7$ & 0.8 \\
\hline Tea and coffee & $2 \cdot 2$ & $1 \cdot 4$ & $3 \cdot 3 \ddagger$ & $1 \cdot 7$ & $2 \cdot 2$ & $1 \cdot 4$ \\
\hline Alcohol & 0.8 & 0.9 & $1 \cdot 0$ & $1 \cdot 4$ & $1 \cdot 3 \ddagger$ & $1 \cdot 5$ \\
\hline Nuts & $0 \cdot 4$ & 0.4 & 0.5 & 0.6 & 0.3 & 0.3 \\
\hline Soups & $0 \cdot 8 \ddagger$ & $1 \cdot 5$ & 0.4 & $0 \cdot 8$ & 0.3 & 0.7 \\
\hline
\end{tabular}

$\ddagger \geq 0.2$ servings/d more than the other two groups. 
Table 2 Characteristics of participants by dietary pattern at baseline: subset of men $(n$ 354) in the Normative Aging Study, Boston, Massachusetts, USA

\begin{tabular}{|c|c|c|c|c|c|c|c|c|c|}
\hline & \multicolumn{3}{|c|}{$\begin{array}{l}\text { Prudent } \\
(n \text { 49) }\end{array}$} & \multicolumn{3}{|c|}{$\begin{array}{l}\text { Unhealthy } \\
(n \text { 105) }\end{array}$} & \multicolumn{3}{|c|}{$\begin{array}{l}\text { High alcohol, low fruit \& vegetables } \\
\qquad(n \text { 200) }\end{array}$} \\
\hline & Mean & SD & $\%$ & Mean & SD & $\%$ & Mean & SD & $\%$ \\
\hline Age (years) & $69 \cdot 4$ & $5 \cdot 2$ & & $66 \cdot 4^{*}$ & $6 \cdot 4$ & & $66 \cdot 0^{\star *}$ & $6 \cdot 6$ & \\
\hline Smoking & & & & & & & & & \\
\hline Current & & & 2 & & & 7 & & & 7 \\
\hline Former & & & 57 & & & 69 & & & 57 \\
\hline Never & & & 41 & & & 25 & & & 37 \\
\hline BMI $\left(\mathrm{kg} / \mathrm{m}^{2}\right)$ & $27 \cdot 9$ & 3.9 & & $27 \cdot 2$ & $3 \cdot 3$ & & $27 \cdot 9$ & $3 \cdot 6$ & \\
\hline Waist:hip ratio & 0.99 & 0.06 & & $1 \cdot 00$ & 0.05 & & $1 \cdot 00$ & 0.05 & \\
\hline \multirow[t]{2}{*}{ Plasma creatinine $(\mu \mathrm{mol} / \mathrm{l})$} & $91 \cdot 7$ & $17 \cdot 9$ & & $93 \cdot 0$ & $17 \cdot 3$ & & $90 \cdot 3$ & $15 \cdot 1$ & \\
\hline & Median & P5, P95 & & Median & P5, P95 & & Median & P5, P95 & \\
\hline Energy intake $(\mathrm{MJ} / \mathrm{d})$ & $9046+t+t$ & 5682,13789 & & $9389+t+t$ & 6274,13590 & & 6938 & 3838,10091 & \\
\hline
\end{tabular}

P5, 5th percentile; P95, 95th percentile.

Mean value was significantly different from that of the prudent pattern: ${ }^{*} P<0.05,{ }^{\star *} P<0.01$

Median value was significantly different from that of the high alcohol, low fruit and vegetable pattern: $++t+P<0 \cdot 0001$

Table 3 Plasma homocysteine and B-vitamin concentrations, and B-vitamin intakes, pre- and post-fortificationł: subset of men ( $n$ 354) in the Normative Aging Study, Boston, Massachusetts, USA

\begin{tabular}{|c|c|c|c|c|c|c|c|c|c|c|c|c|}
\hline & \multicolumn{4}{|c|}{$\begin{array}{l}\text { All men } \\
(n \text { 354) }\end{array}$} & \multicolumn{4}{|c|}{$\begin{array}{l}\text { Supplement non-users } \\
\text { (n 253) }\end{array}$} & \multicolumn{4}{|c|}{$\begin{array}{l}\text { Supplement users } \S \\
(\text { ( } 101)\end{array}$} \\
\hline & \multicolumn{2}{|c|}{ Pre } & \multicolumn{2}{|l|}{ Post } & \multicolumn{2}{|c|}{ Pre } & \multicolumn{2}{|c|}{ Post } & \multicolumn{2}{|c|}{ Pre } & \multicolumn{2}{|c|}{ Post } \\
\hline & Mean & SE & Difference & SE & Mean & SE & Difference & SE & Mean & SE & Difference & SE \\
\hline \multicolumn{13}{|l|}{ Plasma } \\
\hline Homocysteine $(\mu \mathrm{mol} / \mathrm{l})$ & $10 \cdot 7$ & $0 \cdot 2$ & -0.4 & 0.2 & $11 \cdot 0$ & $0 \cdot 2$ & $-0 \cdot 4^{(*)}$ & 0.2 & $10 \cdot 1+$ & 0.4 & $-0 \cdot 2$ & 0.3 \\
\hline Folate (nmol/l) & $21 \cdot 7$ & $1 \cdot 0$ & $+15 \cdot 5^{\star \star \star \star}$ & $1 \cdot 4$ & $19 \cdot 8$ & $0 \cdot 7$ & $+16 \cdot 2^{\star \star \star \star}$ & $1 \cdot 8$ & $26 \cdot 6+t+t$ & $1 \cdot 2$ & $+15 \cdot 4^{\star \star \star \star}$ & $2 \cdot 9$ \\
\hline $\mathrm{B}_{12}(\mathrm{pmol} / \mathrm{l})$ & $340 \cdot 0$ & $8 \cdot 5$ & $+26 \cdot 8^{\star}$ & $12 \cdot 0$ & $325 \cdot 0$ & $8 \cdot 9$ & $+24 \cdot 0^{*}$ & $10 \cdot 4$ & $376 \cdot 0+t$ & $14 \cdot 3$ & $+21 \cdot 0$ & $16 \cdot 8$ \\
\hline $\mathrm{B}_{6}(\mathrm{PLP}, \mathrm{nmol} / \mathrm{l})$ & $80 \cdot 6$ & $4 \cdot 9$ & $+24 \cdot 0^{\star \star \star \star}$ & $6 \cdot 9$ & $63 \cdot 2$ & $5 \cdot 3$ & $+27 \cdot 6^{\star \star \star \star}$ & $6 \cdot 0$ & $126 \cdot 9+t+t$ & $8 \cdot 4$ & $+5 \cdot 5$ & $9 \cdot 8$ \\
\hline \multicolumn{13}{|l|}{$\begin{array}{l}\text { Dietary intake } \\
\quad \text { (without supplements) }\end{array}$} \\
\hline Folate $(\mu \mathrm{g} / \mathrm{d})$ & 335 & 6 & $+100^{\star \star \star \star}$ & 8.9 & 330 & 7 & $+90^{\star \star \star \star}$ & 10 & 348 & 11 & $+92^{\star \star \star \star}$ & 16 \\
\hline$B_{12}(\mu \mathrm{g} / \mathrm{d})$ & $7 \cdot 6$ & $0 \cdot 2$ & $-0 \cdot 9^{\star \star \star}$ & 0.3 & $7 \cdot 7$ & $0 \cdot 3$ & $-1 \cdot 0^{\star \star}$ & 0.3 & $7 \cdot 2$ & 0.5 & -0.9 & 0.5 \\
\hline $\mathrm{B}_{6}(\mathrm{mg} / \mathrm{d})$ & $2 \cdot 2$ & $0 \cdot 1$ & $+0 \cdot 1$ & $0 \cdot 1$ & $2 \cdot 1$ & $0 \cdot 1$ & +0.2 & $0 \cdot 1$ & $2.7+t$ & $0 \cdot 2$ & $-0 \cdot 4^{(\star)}$ & 0.2 \\
\hline
\end{tabular}

PLP, pyridoxal-5-phosphate.

Significance of the change: ${ }^{(\star)} P<0 \cdot 1,{ }^{\star} P<0.05,{ }^{\star \star} P<0.01,{ }^{* \star \star} P<0.001,{ }^{\star \star * \star} P<0.0001$

Mean values were significantly different from those of supplement non-users at baseline: $+P<0.05,++P<0.01,+t++P<0.0001$.

$\ddagger$ Adjusted for education, smoking, waist:hip ratio, age, plasma creatinine and (for dietary variables) energy intake. Supplement use was determined at baseline for this analysis.

$\S$ Use of supplement containing at least one of the B vitamins, i.e. folic acid, vitamin $\mathrm{B}_{6}$ or vitamin $\mathrm{B}_{12}$, at baseline.

decrease in homocysteine concentrations approached significance $(P=0.08)$ in the low fruit and vegetable, high alcohol group. Dietary intake of folate (including from fortified foods) increased significantly in all patterns after fortification $(P<0.001$ for prudent, $P<0 \cdot 0001$ for other two), dietary (non-supplement) intake of vitamin $\mathrm{B}_{12}$ decreased significantly in the high alcohol, low fruit and vegetable group. However, the use of vitamin supplements increased significantly over time in all clusters ( $P<0.05$ for the prudent pattern, $P<0 \cdot 0001$ for other two). When we repeated the analyses with supplement non-users only at both time points, we saw similar results: plasma folate and dietary intake of folate increased significantly in all clusters. We also repeated the analyses for men who remained in the same cluster over time. These results were similar to those described above, despite lower numbers of men in each group (data not shown).

\section{Discussion}

Three dietary patterns were identified by cluster analysis in this group of men: (i) a prudent pattern, with relatively high intakes of fruit, vegetables, low-fat milk and breakfast cereals; (ii) an unhealthy pattern, with high intakes of baked products, sweets and added fats; and (iii) a low fruit and vegetable, relatively high alcohol intake pattern. Following men from before to after fortification of the food supply with folic acid, we saw significant increases in dietary folate intake and plasma folate status in the full group and in all three dietary patterns. In the low fruit and 
Table 4 Plasma homocysteine and B-vitamin concentrations, and B-vitamin intakes, pre- and post-fortification, by dietary pattern at baseline: subset of men ( $n$ 354) in the Normative Aging Study, Boston, Massachusetts, USA

\begin{tabular}{|c|c|c|c|c|c|c|c|c|c|c|c|c|}
\hline & \multicolumn{12}{|c|}{ All men¥ } \\
\hline & \multicolumn{4}{|c|}{ Prudent ( $n$ 49) } & \multicolumn{4}{|c|}{$\begin{array}{l}\text { Unhealthy } \\
(n \text { 105) }\end{array}$} & \multicolumn{4}{|c|}{$\begin{array}{l}\text { High alcohol, low fruit \& vegetables } \\
\qquad(n \text { 200) }\end{array}$} \\
\hline & \multicolumn{2}{|c|}{ Pre } & \multicolumn{2}{|c|}{ Post } & \multicolumn{2}{|c|}{ Pre } & \multicolumn{2}{|c|}{ Post } & \multicolumn{2}{|c|}{ Pre } & \multicolumn{2}{|c|}{ Post } \\
\hline & Mean & SE & Difference & SE & Mean & SE & Difference & SE & Mean & SE & Difference & SE \\
\hline \multicolumn{13}{|l|}{ Plasma } \\
\hline Homocysteine $(\mu \mathrm{mol} / \mathrm{l})$ & $10 \cdot 2$ & 0.5 & -0.02 & 0.5 & $10 \cdot 9$ & $0 \cdot 4$ & $-0 \cdot 2$ & $0 \cdot 4$ & $10 \cdot 7$ & 0.3 & $-0 \cdot 5^{(*)}$ & 0.3 \\
\hline Folate $(\mathrm{nmol} / \mathrm{l})$ & $24 \cdot 3$ & $1 \cdot 8$ & $+16 \cdot 4^{\star \star \star}$ & $4 \cdot 3$ & $21 \cdot 8$ & $1 \cdot 2$ & $+17 \cdot 2^{\star \star \star \star}$ & $3 \cdot 0$ & $21 \cdot 2$ & 0.9 & $+15 \cdot 2^{\star \star \star \star}$ & $2 \cdot 2$ \\
\hline $\mathrm{B}_{12}(\mathrm{pmol} / \mathrm{l})$ & $363 \cdot 0$ & $20 \cdot 0$ & $+3 \cdot 7$ & $24 \cdot 8$ & $358 \cdot 0$ & $14 \cdot 0$ & $+35 \cdot 1^{*}$ & $17 \cdot 3$ & $323 \cdot 0$ & $10 \cdot 0$ & $+21 \cdot 2^{\star}$ & $12 \cdot 7$ \\
\hline $\mathrm{B}_{6}(\mathrm{PLP}, \mathrm{nmol} / \mathrm{l})$ & $88 \cdot 4$ & $12 \cdot 2$ & $+30 \cdot 1^{*}$ & $14 \cdot 3$ & $79 \cdot 4$ & $8 \cdot 4$ & $+17 \cdot 5^{(*)}$ & $10 \cdot 1$ & $80 \cdot 2$ & $6 \cdot 1$ & $+21 \cdot 4^{\star \star \star}$ & $7 \cdot 4$ \\
\hline \multirow{7}{*}{$\begin{array}{l}\text { Intake } \\
\text { Folate }(\mu \mathrm{g} / \mathrm{d}) \\
\mathrm{B}_{12}(\mu \mathrm{g} / \mathrm{d}) \\
B_{6}(\mathrm{mg} / \mathrm{d}) \\
\text { Supplement users (\%) }\end{array}$} & & & & & & & & & & & & \\
\hline & 489 & 17 & $+82^{\star \star *}$ & 24 & $352+t+$ & 12 & $+88^{* \star * *}$ & 17 & $287+t \dagger$ & 8 & $+94^{\star \star \star *}$ & 12 \\
\hline & $9 \cdot 2$ & 0.7 & $-1 \cdot 1$ & 0.8 & $8 \cdot 2$ & 0.5 & -0.5 & $0 \cdot 2$ & $6 \cdot 8$ & 0.4 & $-1 \cdot 2^{* *}$ & $0 \cdot 4$ \\
\hline & $3 \cdot 4$ & $0 \cdot 3$ & -0.3 & $0 \cdot 3$ & $2 \cdot 3+$ & 0.2 & +0.2 & 0.2 & $1.9+t$ & $0 \cdot 1$ & $+0 \cdot 1$ & 0.2 \\
\hline & 39 & & $+16^{\star}$ & & 32 & & $+19^{\star \star \star \star}$ & & 24 & & $+26^{\star \star \star \star}$ & \\
\hline & \multicolumn{12}{|c|}{ Supplement non-users§ } \\
\hline & \multicolumn{4}{|c|}{$(n 30)$} & \multicolumn{4}{|c|}{$(n 71)$} & \multicolumn{4}{|c|}{$(n$ 152) } \\
\hline \multicolumn{13}{|l|}{ Plasma } \\
\hline Homocysteine $(\mu \mathrm{mol} / \mathrm{l})$ & $10 \cdot 3$ & 0.7 & $0 \cdot 1$ & $0 \cdot 7$ & $11 \cdot 5$ & 0.5 & -0.4 & 0.5 & $10 \cdot 9$ & 0.3 & -0.5 & 0.2 \\
\hline Folate $(\mathrm{nmol} / \mathrm{l})$ & $20 \cdot 1$ & $2 \cdot 0$ & $+19 \cdot 9^{\star \star \star}$ & $5 \cdot 7$ & $20 \cdot 7$ & $1 \cdot 3$ & $+17 \cdot 1^{\star \star \star \star}$ & $3 \cdot 8$ & $19 \cdot 4$ & 0.9 & $+15 \cdot 7^{\star \star \star \star}$ & $2 \cdot 5$ \\
\hline $\mathrm{B}_{12}(\mathrm{pmol} / \mathrm{l})$ & $336 \cdot 0$ & $25 \cdot 0$ & $+9 \cdot 1$ & $29 \cdot 3$ & $343 \cdot 0$ & $16 \cdot 0$ & $+36 \cdot 2^{(*)}$ & $19 \cdot 7$ & $312 \cdot 0$ & $11 \cdot 0$ & $+22 \cdot 3^{(*)}$ & $13 \cdot 2$ \\
\hline $\mathrm{B}_{6}(\mathrm{PLP}, \mathrm{nmol} / \mathrm{l})$ & 63.9 & 6.5 & $29 \cdot 2^{(*)}$ & $15 \cdot 6$ & $62 \cdot 2$ & $4 \cdot 2$ & $+31 \cdot 7^{* *}$ & $10 \cdot 6$ & $62 \cdot 6$ & 2.9 & $+24 \cdot 7^{\star \star \star}$ & $7 \cdot 2$ \\
\hline \multicolumn{13}{|l|}{ Intake } \\
\hline Folate $(\mu \mathrm{g} / \mathrm{d})$ & 476 & 21 & $+87^{\star *}$ & 30 & 340 & 14 & $+72^{\star \star *}$ & 21 & 289 & 10 & $+96^{\star \star \star \star}$ & 14 \\
\hline$B_{12}(\mu g / d)$ & $7 \cdot 6$ & 0.9 & -0.44 & 0.98 & $8 \cdot 3$ & 0.6 & $-1 \cdot 4^{*}$ & 0.6 & $7 \cdot 2$ & 0.4 & $-0.9^{*}$ & 0.4 \\
\hline $\mathrm{B}_{6}(\mathrm{mg} / \mathrm{d})$ & $2 \cdot 7$ & $0 \cdot 1$ & +0.22 & $0 \cdot 15$ & $2 \cdot 2$ & 0.1 & +0.15 & 0.10 & 1.8 & 0.1 & $+0.18^{\star \star}$ & 0.07 \\
\hline
\end{tabular}

PLP, pyridoxal-5-phosphate.

Significance of the change: ${ }^{(*)} P<0 \cdot 1,{ }^{\star} P<0.05,{ }^{* \star} P<0.01,{ }^{* \star \star} P<0.001,{ }^{\star * \star *} P<0.0001$.

Mean values were significantly different from those of the prudent pattern: $+P<0.05,++P<0.01,+t+P<0.001$

$\ddagger$ Adjusted for education, smoking, waist:hip ratio, age, plasma creatinine, supplement use and (for dietary variables) energy intake.

§Adjusted for education, smoking, waist:hip ratio, age, plasma creatinine and (for dietary variables) energy intake.

vegetable, high alcohol group, homocysteine concentration showed a tendency to decrease, but did not reach statistical significance.

Advantages of the present study include the longitudinal design and the availability of information on dietary intake, supplement use and plasma vitamin and homocysteine measures both before and after folic acid fortification. However, the study also has some limitations. Only men were included, so no conclusions can be made for women. Dietary intake data were obtained by FFQ and patterns were based on reported number of servings per day rather than as a percentage of total energy. However, we adjusted our models for energy intake. The reported energy intake in the low fruit and vegetable, high alcohol cluster was lower compared with the prudent and unhealthy dietary pattern groups. A possible explanation is that individuals in the low fruit and vegetable, high alcohol cluster underreport their alcohol intake. There is some evidence that heavy drinkers are more likely to under-report their alcohol use than light drinkers ${ }^{(24)}$.

Cluster analysis is a commonly used method for empirically deriving eating patterns, and is based on individual differences in mean dietary intakes ${ }^{(25)}$. Similar patterns defined by cluster or factor analysis have been found in other studies ${ }^{(11-13,26-30)}$. Villegas et al. identified a traditional Irish diet characterized by high intake of saturated fat, a prudent diet and an alcohol and convenience food pattern, using cluster analysis ${ }^{(12)}$. In the Health Professionals' Follow-up Study, two major dietary patterns were derived by factor analysis: a prudent dietary pattern and a Western dietary pattern ${ }^{(13,26)}$. Newby et al. also found a healthy, a Western and an alcohol dietary pattern in the Swedish Mammography Cohort and in the Baltimore Longitudinal Study of Aging ${ }^{(29,30)}$. Ganji and Kafai found that folate status improved significantly and homocysteine concentrations decreased significantly in participants in the National Health and Nutrition Examination Survey, after fortification with folic acid ${ }^{(31)}$. Consistent with our findings, Jacques et $a l .{ }^{(15)}$ found a pre-post fortification increase in mean plasma folate concentrations and a decrease in homocysteine concentrations among Framingham Heart Study participants who did not use vitamin supplements. Among vitamin supplement users, mean plasma folate also increased, but no change in homocysteine concentrations were observed. Other studies showed an increase in folate concentrations after fortification, but homocysteine concentrations were not reported in these studies and supplement use was not taken into account ${ }^{(31-33)}$. The effects of folic acid fortification on health remain controversial, and it is important to understand how it may affect different 
subsets of the population. While studies have been conducted in different nationalities, age groups and health status groups ${ }^{(34)}$, dietary patterns were not investigated in any of these previous studies.

As we hypothesized, no meaningful change in homocysteine was observed for the prudent dietary pattern. This is likely because folate status was adequate before fortification, leaving little room for improvement. Although it appeared to decrease in the other two dietary pattern groups, this approached significance only in the low fruit and vegetable, high alcohol pattern. However, because homocysteine tends to increase with age, the observed decreases could be considered conservative, as prevention of an increase may be included. Further, it is likely that the observed decreases would have been significant with larger sample sizes.

The increased use of supplements from before to after folic acid fortification could explain some of the increases in vitamin $B_{12}$ and $B_{6}$ status. However, after excluding men who were taking vitamin supplements, increases in plasma vitamin $\mathrm{B}_{6}$ and plasma $\mathrm{B}_{12}$ persisted. In one other study, serum vitamin $B_{12}$ concentrations were also seen to increase significantly in the US population between the pre- and post-folic acid fortification periods in elderly persons ${ }^{(35)}$. Folic acid fortification was undertaken to reduce the risk of neural-tube defects, but it was hoped that it would also have a beneficial effect on vascular diseases, cognitive function and even mortality, because of the association between inadequate folate intake and higher circulating homocysteine concentrations ${ }^{(1-7,14,17)}$. However, we found that the pre-post fortification decrease in homocysteine was small, despite greater use of supplements as well as fortification over this time period. Andersen et al. saw larger decreases in homocysteine concentrations (from 13.8 to $12.3 \mu \mathrm{mol} / \mathrm{l}$, $P<0 \cdot 001)$ after folic acid fortification, but the effect on mortality was minor and likely attributable to other factors $^{(36)}$. Two recent meta-analyses showed that a $25 \%$ reduction of plasma homocysteine was associated with an $11-16 \%$ decrease in risk of IHD and a 19-22\% decrease in risk of stroke ${ }^{(3,37)}$. However, thus far, most studies have focused on the homocysteine-lowering effects of folate ${ }^{(5,28)}$. Recently, benefits of folate independent of homocysteine lowering have been reported ${ }^{(36-42)}$. For example, Voutilainen et al. showed that moderate-to-high serum folate concentrations were associated with a greatly reduced incidence of acute coronary events ${ }^{(41)}$. More studies are needed to investigate whether this level of fortification will influence cardiovascular morbidity and mortality.

In conclusion, dietary intake of folate and plasma folate increased significantly in this sample of men after fortifying enriched cereal-grain products with $140 \mu \mathrm{g} / 100 \mathrm{~g}$, and in all subsets examined, including supplement users and nonusers and all dietary pattern groups. However, improvements in homocysteine were small and approached significance only in the low fruit and vegetable, high alcohol group. Larger studies are needed to get more definitive assessments of the effects of folic acid fortification on differing subsets of the population.

\section{Acknowledgements}

The research was supported in part by the US Department of Agriculture Cooperative Agreement 58-1950-7-707 and by the organization Stichting De Drie Lichten. The latter organization did not participate in the design or conduct of the study; in the collection, analysis or interpretation of the data; or in the preparation, review or approval of the manuscript. All authors contributed to the revisions and drafts of this manuscript and reviewed the final version. A.S. 3rd and K.L.T. contributed to study concept and design; K.L.T., K.T.B.K. and D.K. contributed to analysis and interpretation of the data; K.T.B.K. drafted the manuscript; K.L.T., D.K., L.C.P.G.M.d.G. and W.A.v.S. conducted critical revision of the manuscript. None of the authors had a personal or professional conflict of interest.

\section{References}

1. Nygard O, Vollset SE, Refsum H, Stensvold I, Tverdal A, Nordrehaug JE, Ueland M \& Kvale G (1995) Total plasma homocysteine and cardiovascular risk profile. The Hordaland Homocysteine Study. JAMA 274, 1526-1533.

2. Graham IM, Daly LE, Refsum HM et al. (1997) Plasma homocysteine as a risk factor for vascular disease. The European Concerted Action Project. JAMA 277, 1775-1781.

3. Homocysteine Studies Collaboration (2002) Homocysteine and risk of ischemic heart disease and stroke: a metaanalysis. JAMA 288, 2015-2022.

4. Bostom AG, Rosenberg IH, Silbershatz H, Jacques PF, Selhub J, D'Agostino RB, Wilson PW \& Wolf PA (1999) Nonfasting plasma total homocysteine levels and stroke incidence in elderly persons: the Framingham Study. Ann Intern Med 131, 352-355.

5. Tucker KL, Qiao N, Scott T, Rosenberg I \& Spiro A 3rd (2005) High homocysteine and low B vitamins predict cognitive decline in aging men: the Veterans Affairs Normative Aging Study. Am J Clin Nutr 82, 627-635.

6. McLean RR, Jacques PF, Selhub J, Tucker KL, Samelson EJ, Broe KE, Hannan MT, Cupples LA \& Kiel DP (2004) Homocysteine as a predictive factor for hip fracture in older persons. N Engl J Med 350, 2042-2049.

7. Nygard O, Nordrehaug JE, Refsum H, Ueland PM, Farstad M \& Vollset SE (1997) Plasma homocysteine levels and mortality in patients with coronary artery disease. $N$ Engl J Med 337, 230-236.

8. Homocysteine Lowering Trialists' Collaboration (2005) Dose-dependent effects of folic acid on blood concentrations of homocysteine: a meta-analysis of the randomized trials. Am J Clin Nutr 82, 806-812.

9. Panagiotakos DB, Pitsavos C, Zeimbekis A, Chrysohoou C \& Stefanadis C (2005) The association between lifestylerelated factors and plasma homocysteine levels in healthy individuals from the 'ATTICA' Study. Int J Cardiol 98, 471-477.

10. Verhoef P \& de Groot LC (2005) Dietary determinants of plasma homocysteine concentrations. Semin Vasc Med $\mathbf{5}$, 110-123. 
11. Gao X, Yao M, McCrory MA, Ma G, Li Y, Roberts SB \& Tucker KL (2003) Dietary pattern is associated with homocysteine and B vitamin status in an urban Chinese population. J Nutr 133, 3636-3642.

12. Villegas R, Salim A, Collins MM, Flynn A \& Perry IJ (2004) Dietary patterns in middle-aged Irish men and women defined by cluster analysis. Public Health Nutr 7, 1017-1024.

13. Fung TT, Rimm EB, Spiegelman D, Rifai N, Tofler GH, Willett WC \& Hu FB (2001) Association between dietary patterns and plasma biomarkers of obesity and cardiovascular disease risk. Am J Clin Nutr 73, 61-67.

14. Food and Drug Administration (1996) Food standards: amendment of standards of identity for enriched grain products to require addition of folic acid. Fed Regist $\mathbf{6 1}$, 8781-8797.

15. Jacques PF, Selhub J, Bostom AG, Wilson PW \& Rosenberg IH (1999) The effect of folic acid fortification on plasma folate and total homocysteine concentrations. N Engl J Med 340, 1449-1454.

16. Choumenkovitch SF, Selhub J, Wilson PW, Rader JI, Rosenberg IH \& Jacques PF (2002) Folic acid intake from fortification in United States exceeds predictions. I Nutr 132, 2792-2798.

17. Tucker KL, Mahnken B, Wilson PW, Jacques P \& Selhub J (1996) Folic acid fortification of the food supply. Potential benefits and risks for the elderly population. JAMA $\mathbf{2 7 6}$, 1879-1885.

18. Todaro JF, Shen BJ, Niaura R, Spiro A 3rd \& Ward KD (2003) Effect of negative emotions on frequency of coronary heart disease (The Normative Aging Study). Am J Cardiol 92, 901-906.

19. Jacques PF, Sulsky SI, Sadowski JA, Philips JC, Rush D \& Willett WC (1993) Comparison of micronutrient intake measured by a dietary questionnaire and biochemical indicators of micronutrient status. Am J Clin Nutr 57, 182-189.

20. Tucker KL, Rich S, Rosenberg I, Jacques P, Dallal G, Wilson PW \& Selhub J (2000) Plasma vitamin B-12 concentrations relate to intake source in the Framingham Offspring study. Am J Clin Nutr 71, 514-522.

21. Araki A \& Sako Y (1987) Determination of free and total homocysteine in human plasma by high-performance liquid chromatography with fluorescence detection. J Chromatogr 422, 43-52.

22. Selhub J, Jacques PF, Wilson PW, Rush D \& Rosenberg IH (1993) Vitamin status and intake as primary determinants of homocysteinemia in an elderly population. JAMA 270, 2693-2698.

23. Shin-Buehring Y, Rasshofer R \& Endres W (1981) A new enzymatic method for pyridoxal-5'-phosphate determination. I Inherit Metab Dis 4, 123-124.

24. Feunekes GI, van't Veer P, van Staveren WA \& Kok FJ (1999) Alcohol intake assessment: the sober facts. Am J Epidemiol 150, 105-112.

25. Jacques PF \& Tucker KL (2001) Are dietary patterns useful for understanding the role of diet in chronic disease? Am J Clin Nutr 73, 1-2.

26. Hu FB, Rimm E, Smith-Warner SA, Feskanich D, Stampfer MJ, Ascherio A, Sampson L \& Willett WC (1999) Reproducibility and validity of dietary patterns assessed with a foodfrequency questionnaire. Am J Clin Nutr 69, 243-249.

27. Millen BE, Quatromoni PA, Pencina M, Kimokoti R, Nam BH, Cobain S, Kozak W, Appugliese DP, Ordovas J \&
D'Agostino RB (2005) Unique dietary patterns and chronic disease risk profiles of adult men: the Framingham nutrition studies. J Am Diet Assoc 105, 1723-1734.

28. Millen BE, Quatromoni PA, Copenhafer DL, Demissie S, O'Horo CE \& D'Agostino RB (2001) Validation of a dietary pattern approach for evaluating nutritional risk: the Framingham Nutrition Studies. J Am Diet Assoc 101, 187-194.

29. Newby PK, Muller D \& Tucker KL (2004) Associations of empirically derived eating patterns with plasma lipid biomarkers: a comparison of factor and cluster analysis methods. Am J Clin Nutr 80, 759-767.

30. Newby PK, Weismayer C, Akesson A, Tucker KL \& Wolk A (2006) Long-term stability of food patterns identified by use of factor analysis among Swedish women. J Nutr 136, 626-633.

31. Ganji V \& Kafai MR (2006) Trends in serum folate, RBC folate, and circulating total homocysteine concentrations in the United States: analysis of data from National Health and Nutrition Examination Surveys, 1988-1994, 1999-2000, and 2001-2002. J Nutr 136, 153-158.

32. Lawrence JM, Petitti DB, Watkins M \& Umekubo MA (1999) Trends in serum folate after food fortification. Lancet $\mathbf{3 5 4}$, 915-916.

33. Choumenkovitch SF, Jacques PF, Nadeau MR, Wilson PW, Rosenberg IH \& Selhub J (2001) Folic acid fortification increases red blood cell folate concentrations in the Framingham study. J Nutr 131, 3277-3280.

34. Smith AD, Kim YI \& Refsum H (2008) Is folic acid good for everyone? Am J Clin Nutr 87, 517-533.

35. Pfeiffer CM, Caudill SP, Gunter EW, Osterloh J \& Sampson EJ (2005) Biochemical indicators of B vitamin status in the US population after folic acid fortification: results from the National Health and Nutrition Examination Survey 1999-2000. Am J Clin Nutr 82, 442-450.

36. Anderson JL, Jensen KR, Carlquist JF, Bair TL, Horne BD \& Muhlestein JB (2004) Effect of folic acid fortification of food on homocysteine-related mortality. Am J Med 116, 158-164.

37. Wald DS, Law M \& Morris JK (2002) Homocysteine and cardiovascular disease: evidence on causality from a metaanalysis. BMJ 325, 1202

38. de Bree A, Verschuren WM, Blom HJ, Nadeau M, Trijbels FJ \& Kromhout D (2003) Coronary heart disease mortality, plasma homocysteine, and B-vitamins: a prospective study. Atherosclerosis 166, 369-377.

39. Verhaar MC, Stroes E \& Rabelink TJ (2002) Folates and cardiovascular disease. Arterioscler Thromb Vasc Biol 22, 6-13.

40. Verhaar MC, Wever RM, Kastelein JJ, van Dam T, Koomans HA \& Rabelink TJ (1998) 5-Methyltetrahydrofolate, the active form of folic acid, restores endothelial function in familial hypercholesterolemia. Circulation 97, 237-241.

41. Voutilainen S, Virtanen JK, Rissanen TH et al. (2004) Serum folate and homocysteine and the incidence of acute coronary events: the Kuopio Ischaemic Heart Disease Risk Factor Study. Am J Clin Nutr 80, 317-323.

42. Voutilainen S, Lakka TA, Porkkala-Sarataho E, Rissanen T, Kaplan GA \& Salonen JT (2000) Low serum folate concentrations are associated with an excess incidence of acute coronary events: the Kuopio Ischaemic Heart Disease Risk Factor Study. Eur J Clin Nutr 54, 424-428. 